\title{
Time-domain harmonic extraction algorithms for three-level inverter-based shunt active power filter under steady-state and dynamic-state conditions-an evaluation study
}

\author{
Ali Saadon Al-Ogaili ${ }^{1}$, Agileswari Ramasamy ${ }^{2}$, Yap Hoon ${ }^{3}$, Renuga Verayiah ${ }^{4}$, \\ Marayati Marsadek ${ }^{5}$, Tengku Juhana ${ }^{6}$, Nur Azzammudin Rahmat ${ }^{7}$ \\ ${ }^{1,5}$ Institute of Power Engineering (IPE), Universiti Tenaga Nasional, Malaysia \\ ${ }^{2,4,6,7}$ Department of Electrical and Electronics Engineering, Universiti Tenaga Nasional, Malaysia \\ ${ }^{3}$ School of Engineering, Faculty of Innovation and Technology, Taylor's University, Malaysia
}

\begin{tabular}{l}
\hline \hline Article Info \\
\hline Article history: \\
Received Jul 18, 2019 \\
Revised Mar 5, 2020 \\
Accepted Mar 17, 2020 \\
\hline
\end{tabular}

Keywords:

Active power filter Current harmonics mitigation DQ Theory Multilevel converter Power quality PQ theory

\begin{abstract}
Power quality is a major consideration in all office equipment, manufacturies and residential home appliances. Harmonic distortion is one of the crucial power quality issues. In order to mitigate the harmonic distortion, the performance of shunt active power filter (SAPF) is judged in terms of the accuracy and response time of its designed controller. In this context, the controller consists of three parts: harmonic extraction, switching control, and DC-link capacitor. The harmonic extraction technique serves the major role of deriving the required reference current to ensure successful mitigation of current harmonics by SAPF. Among the existing techniques, harmonic extraction algorithms based on time-domain approaches are most widely applied as they offer simple implementation features with increased speed and reduced computational burden. This paper presents detailed investigation and analysis regarding the performance of two famous time-domain harmonic extraction techniques namely, synchronous reference frame (SRF) and instantaneous power (PQ) theory. Extensive simulation work is conducted in MATLAB-Simulink platform under two conditions, which are, steady-state conditions and dynamic-state conditions, considering various highly nonlinear loads. For evaluation purposes, each control algorithm is incorporated into the controller of a three-phase SAPF, developed using a three-level neutral-point-clamped (NPC) inverter. Comprehensive results are provided to confirm mitigation performance of the SAPF utilizing each harmonic extraction algorithm.
\end{abstract}

Copyright $@ 2020$ Institute of Advanced Engineering and Science. All rights reserved.

Corresponding Author:

Ali Saadon Al-Ogaili, Institute of Power Engineering (IPE), Universiti Tenaga Nasional, 43000 Kajang, Selangor, Malaysia.

Email: alinasrieh.edu@gmail.com

\section{INTRODUCTION}

Extensive applications of harmonic-producing loads have posted severe power quality issues especially low power factors and high harmonic distortion to electricity grid. This has raised alerting concerns among researchers in formulating efficient solution. Among the state-of-art-techniques, SAPF is the most powerful technique for solving current harmonics [1-3]. Additionally, it also improves power factor (PF) performance of power system by ensuring in-phase operation of source current with its corresponding source voltage. Generally, SAPF recovers the sinusoidal characteristics (with fundamental frequency) of the source current, by injecting a corrective current back to the polluted power system. 
Traditionally, standard two-level inverter is mostly applied as the topology for SAPF. However, three-level inverters are extensively utilized in several applications, such as motor drives and pulse-width modulations (PWM) [4-8] for their benefits of lower harmonic outputs. The current harmonic extraction algorithm serves a major role in developing the required reference current to control the designated SAPF in minimizing the harmonic distortion. Recently, intensive studies on this algorithm have been investigated and were basically categorized under three distinctive groups namely time-domain, frequency-domain and machine learning techniques [9-15].

Nevertheless, harmonic extraction algorithms categorized under time-domain technique are always dominant since they provide simple implementation features with increased speed and reduced computational burden. SRF [16, 17], power PQ theory [5, 18, 19] algorithms are the two most popular algorithms under time-domain technique category. Current resulted under the influence of nonlinear load such as uncontrolled bridge rectifier will particularly contain fundamental and harmonic components, respectively. These components will appear as DC signal and AC signal, respectively in two-phase stationary reference frame when they are converted from three-phase $a b c$ natural frame.

The accuracy of the detected fundamental component is most important in SRF and PQ theory when they are applied in harmonic extraction application. In both algorithms, the desired fundamental component are commonly achieved by using indirect detection approach [20], i.e., using numerical Butterworth-type low-pass filter (LPF). Basically, the conduct of the LPF method is depending on the harmonic order selection. Therefore, the numerical LPF must be tuned to ensure optimum fundamental component detection, so as to achieve optimum harmonic extraction performance. Improper tuning may result in significant time delay and excessive distortions during the harmonic extraction process. According to [21, 22], the second order filter best suit the purpose of fundamental component detection as higher order filter will increase computational problem to the controller. Meanwhile, cutting frequency of $10 \mathrm{~Hz}$ is most widely applied and is recognized as the best value to achieve efficient fundamental component detection performance.

Various comparative studies [23-26] have been reported to compare the effectiveness of SRF and PQ theory based harmonic extraction techniques. However, most reported comparative studies focused solely on steady-state conditions with single nonlinear load [23, 25] and no further analyses have been conducted on dynamic-state applications which occurs regularly in power system, therefore insufficient to describe performances of the harmonic extraction algorithms involved. Other comparative studies which involve various distorted and unbalanced source voltage conditions [24, 26] have also been conducted. However, it is unnecessary to investigate their performances under distorted and unbalanced source voltage system, since SAPFs are mostly designed to work in balanced source voltage system. Besides, there is no specific and good comparative work focusing on the effect of cutting frequency variation towards harmonic extraction performances of SRF and PQ theory techniques have been done yet. Complete understanding on the relationship between cutting frequency and harmonic extraction performances contribute greatly to achieving accurate and fast mitigation performance of SAPF.

The findings of this paper can provide important insight to new researchers in deciding the relevant algorithm and the type of analysis to consider in their respective work. Overall, this paper provides comprehensive comparative evaluation on two types of harmonic extraction algorithms which are developed based on SRF and PQ theory, respectively. A simulation model of three-phase SAPF utilizing a three-level neutral-point-clamped (NPC) inverter is developed in MATLAB-Simulink platform to aid the analysis. To enhance contribution of this work, the evaluation takes into consideration both steady-state and dynamic-state conditions, and various highly nonlinear loads. In addition, the effects of cutting frequency variation on each algorithm towards mitigation performances of SAPF are also thoroughly investigated.

The remaining sections of the manuscript is structured as follows. The structure of SAPF and its control schemes is clarified in section 2. The analysis of the two famous time-domain harmonic extraction algorithms is explained in section 3. The simulation results are presented and discussed in section 4 by highlighting performances of each harmonic extraction algorithm. Finally, the conclusion is provided in section 5, which summarizes the significant findings of this paper.

\section{SAPF AND ASSOCIATED CONTROL TECHNIQUES}

The overall structure of three-phase NPC inverter based SAPF is shown in Figure 1. As can be seen in this figure, a typical SAPF circuit connection in a power system will have a SAPF linked at the junction point of common coupling (PCC), and in among with a power supply (in this case is three-phase supply) and nonlinear rectifier load. The rectifier load is commonly combined to either capacitive load (RC), inductive load (RL), or resistive load (R), as shown in Figure 1(a). In this work, the controller applied for managing operation of SAPF comprises of switching control, voltage balancing control for individual capacitor, overall DC-link voltage control and harmonic extraction. 
Nevertheless, this work is focusing solely on evaluating the performance of harmonic extraction technique. In order to perform this evaluation, other control algorithms will be made similar when evaluating the desired harmonic extraction technique, as shown in Figure 1(b). For DC-link voltage control, a proportional-integral (PI) is used [4, 22]. Next, to balance the voltage of splitting DC-link capacitors, a voltage feedback control technique $[27,28]$ is applied. Finally, to control the switching function of the SAPF, a space vector pulse width modulation (SVPWM) [27-29] is used.

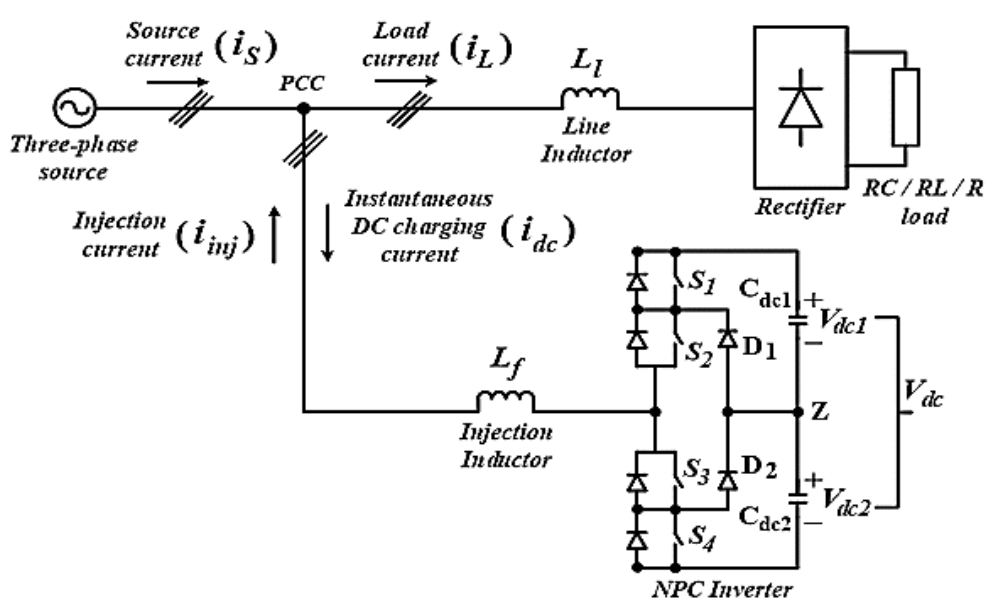

(a)

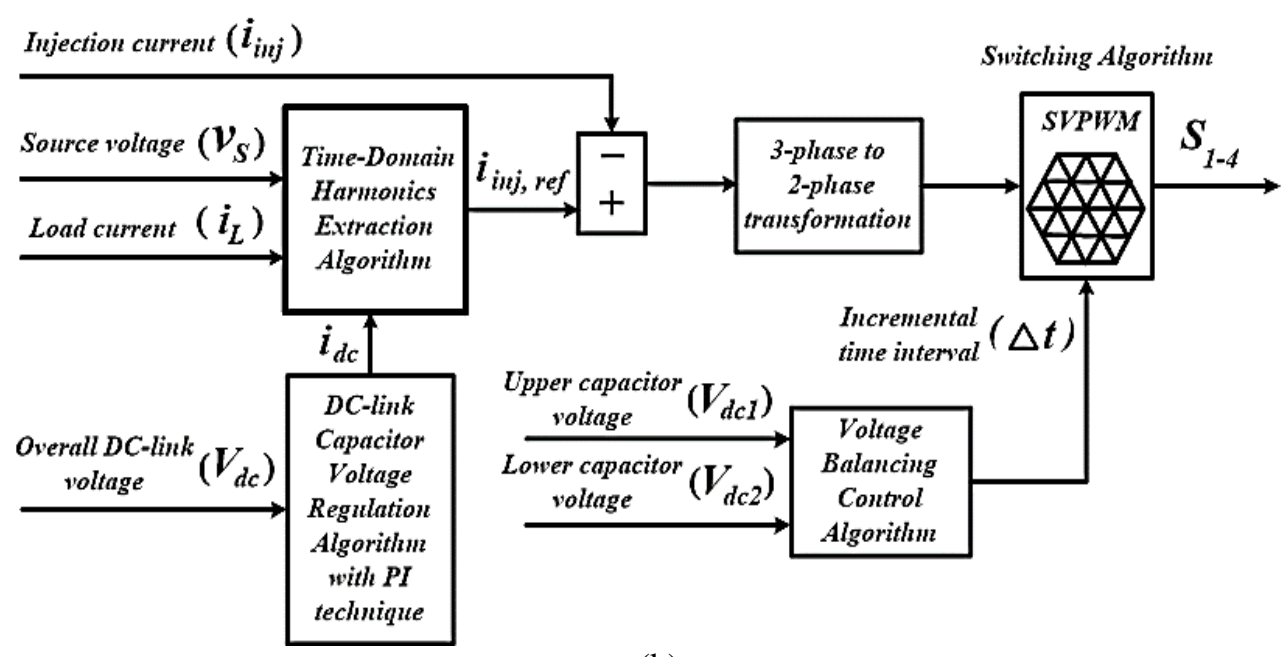

(b)

Figure 1. General structure of three-phase three-level NPC inverter-based SAPF configuration, (a) block diagram and (b) controller strucure

\section{TIME-DOMAIN HARMONIC EXTRACTION ALGORITHM}

In this section, working principles of the two harmonic extraction algorithms considered in this work, namely, SRF and PQ theory are discussed in detail. Moreover, comparative evaluation is presented, highlighting their respective distinctive features. The special features of each algorithm are contrasted in such as way that will be able to identify the respective strengths and weaknesses of the algorithms, eventually select the most suitable algorithm for their works.

\subsection{SRF}

Based on Figure 2(a), SRF technique utilizes Park-transformation to perform harmonic extraction. The transformation can be used to rotate the reference frames of three-phase AC waveforms such that they become DC signals (in this paper, it is used to convert the $a b c$ natural frame to $d q$ rotating frames). In this context, the load current $i_{L a b c}$ is transformed into $I_{L d q}$, and then the harmonic components are being isolated from its fundamental component. The Park transformation method can be outlined as follow: 


$$
\left[\begin{array}{l}
I_{L d} \\
I_{L q}
\end{array}\right]=\frac{2}{3}\left[\begin{array}{ccc}
\sin (\omega t) & \sin \left(\omega t-\frac{2 \pi}{3}\right) & \sin \left(\omega t+\frac{2 \pi}{3}\right) \\
\cos (\omega t) & \cos \left(\omega t-\frac{2 \pi}{3}\right) & \cos \left(\omega t+\frac{2 \pi}{3}\right)
\end{array}\right]\left[\begin{array}{l}
i_{L a} \\
i_{L b} \\
i_{L c}
\end{array}\right]
$$

where $\omega t$ is the transformation angle.

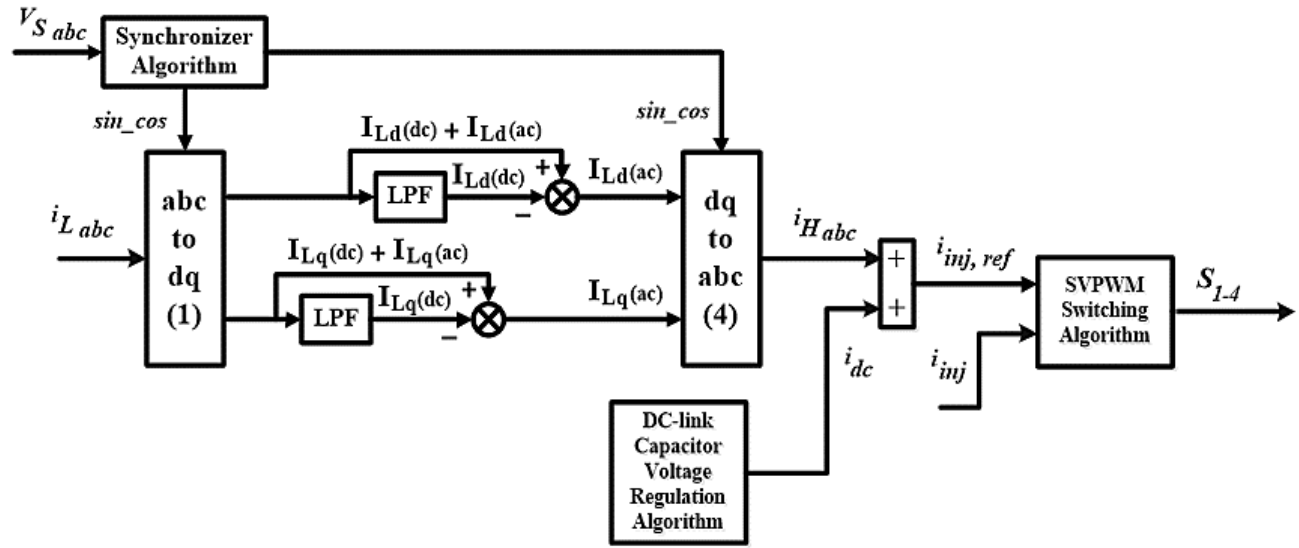

(a)

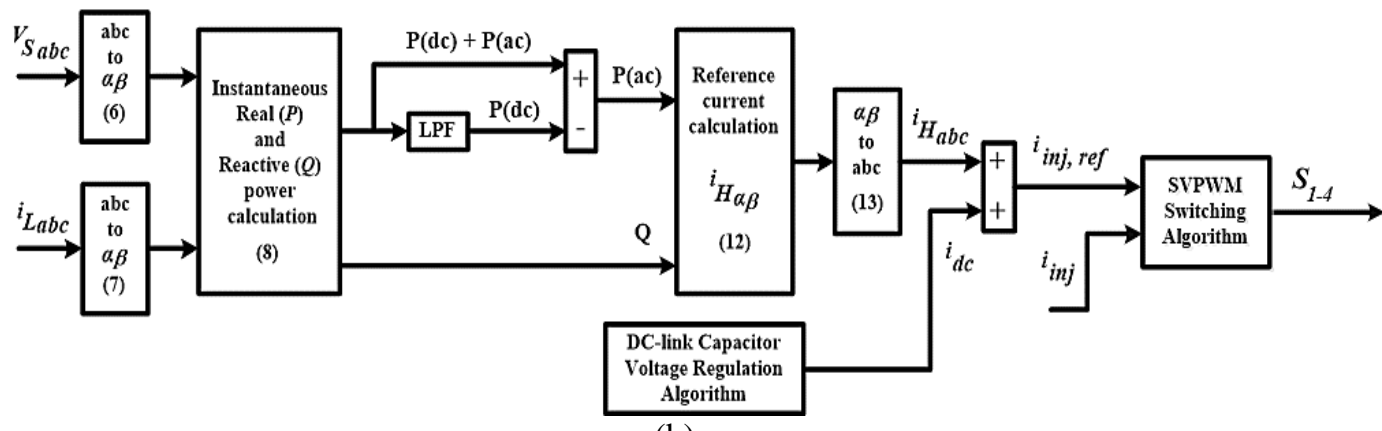

(b)

Figure 2. Structure of harmonic extraction algorithm according to, (a) SRF and (b) PQ theory

Due to connection of harmonic-producing loads, $I_{L d}$ and $I_{L q}$ currents are contaminated by the current harmonics produced and as a result, the load current expression can now be interpreted as:

$$
\left[\begin{array}{l}
I_{L d} \\
I_{L q}
\end{array}\right]=\left[\begin{array}{ll}
I_{L d(d c)}+ & I_{L d(a c)} \\
I_{L q(d c)}+ & I_{L q(a c)}
\end{array}\right]
$$

where $I_{L d(d c)}$ is the fundamental components of the load current represented in $d$ frame, $I_{L d(a c)}$ is harmonic component of the load current represented in $d$ frame, $I_{L q(d c)}$ is the fundamental component of the load current represented in $q$ frame, $I_{L q(a c)}$ is harmonic component of the load current represented in $q$ frame.

In $d q$ rotating frame, the $a c$ components are key components needed to derive the required reference current. In this regard, indirect detection approach [20] expressed in (3) is applied. According to this approach, the $d c$ components will first be detected by using tuned numerical Butterworth-type LPF, and then the detected $d c$ components will be removed from the actual $I_{L d}$ and $I_{L q}$ components.

$$
\left[\begin{array}{l}
I_{L d(a c)} \\
I_{L q(a c)}
\end{array}\right]=\left[\begin{array}{l}
I_{L d}-I_{L d(d c)} \\
I_{L q}-I_{L q(d c)}
\end{array}\right]
$$

Once $a c$ components $\left(I_{L d(a c)}\right.$ and $\left.I_{L q(a c)}\right)$ are achieved, inverse Park-transformation given in (4) is used to transform the $a c$ components back to their equivalent three-phase harmonic current $\left(i_{H a b c}\right)$. 


$$
\left[\begin{array}{c}
i_{H_{a}} \\
i_{H_{b}} \\
i_{H_{c}}
\end{array}\right]=\left[\begin{array}{cc}
\sin (\omega t) & \cos (\omega t) \\
\sin \left(\omega t-\frac{2 \pi}{3}\right) & \cos \left(\mathrm{ù} t-\frac{2 \pi}{3}\right) \\
\sin \left(\omega t+\frac{2 \pi}{3}\right) & \cos \left(\omega t+\frac{2 \pi}{3}\right)
\end{array}\right]\left[\begin{array}{l}
I_{L d(a c)} \\
I_{L q(a c)}
\end{array}\right]
$$

The reference injection current is obtained by using the following equation:

$$
i_{\text {inj,ref }}=i_{H_{a b c}}+i_{d c}
$$

where $i_{d c}$ is the DC charging current.

\subsection{PQ Theory}

According to Figure 2(b), a computational process for instantaneous power (in $\alpha-\beta$ coordinates) are required to model harmonic extraction process according to the principle of $\mathrm{PQ}$ theory. Initially, the measured source voltage and load current in three-phase $a b c$ coordinates are transformed to $\alpha-\beta$ coordinates by means of Clarke-transformation given as:

$$
\begin{aligned}
& {\left[\begin{array}{l}
v_{\alpha} \\
v_{\beta}
\end{array}\right]=\sqrt{\frac{2}{3}}\left[\begin{array}{ccc}
1 & -\frac{1}{2} & -\frac{1}{2} \\
0 & \frac{\sqrt{3}}{2} & -\frac{\sqrt{3}}{2}
\end{array}\right]\left[\begin{array}{c}
v_{a} \\
v_{b} \\
v_{c}
\end{array}\right]} \\
& {\left[\begin{array}{l}
i_{\alpha} \\
i_{\beta}
\end{array}\right]=\sqrt{\frac{2}{3}}\left[\begin{array}{ccc}
1 & -\frac{1}{2} & -\frac{1}{2} \\
0 & \frac{\sqrt{3}}{2} & -\frac{\sqrt{3}}{2}
\end{array}\right]\left[\begin{array}{l}
i_{a} \\
i_{b} \\
i_{c}
\end{array}\right]}
\end{aligned}
$$

where $v_{a}, v_{b}$, and $v_{c}$ are the three-phase voltages and $i_{a}, i_{b}$, and $i_{c}$ are the three-phase currents. Subsequently, the active power $P$ and reactive power $Q$ in $\alpha-\beta$ coordinates are expressed as:

$$
\left[\begin{array}{l}
P \\
Q
\end{array}\right]=\left[\begin{array}{cc}
v_{\alpha} & v_{\beta} \\
-v_{\beta} & v_{\alpha}
\end{array}\right]\left[\begin{array}{l}
i_{\alpha} \\
i_{\beta}
\end{array}\right]
$$

Similarly, due to the presence of harmonic-producing load, the actual $P$ and $Q$ components are contaminated by the current harmonics generated and can be represented as:

$$
\left[\begin{array}{l}
P \\
Q
\end{array}\right]=\left[\begin{array}{l}
P_{d c}+P_{a c} \\
Q_{d c}+Q_{a c}
\end{array}\right]
$$

where $P_{d c}$ is the fundamental component of the instantaneous active power, $P_{a c}$ is the distorted component of the instantaneous active power, $Q_{d c}$ is the fundamental component of the instantaneous reactive power, and $Q_{a c}$ is the distorted component of the instantaneous reactive power. In the harmonic extraction application, only the distorted component $P_{a c}$ is required for deriving the reference current. Similar to SRF algorithm, the required $a c$ component, $P_{a c}$ is obtained via indirect detection approach [20]. This is done by the fundamental component $P_{d c}$ is first detected by the tuned numerical Butterworth-type LPF and is then removed from the original $P$ value. This method can be expressed as:

$$
P_{a c}=P-P_{d c}
$$

With the removal of $P_{d c}$ component, (8) can be rewritten as:

$$
\left[\begin{array}{c}
P_{\mathrm{ac}} \\
Q
\end{array}\right]=\left[\begin{array}{cc}
v_{\alpha} & v_{\beta} \\
-v_{\beta} & v_{\alpha}
\end{array}\right]\left[\begin{array}{c}
i_{H_{\alpha}} \\
i_{H_{\beta}}
\end{array}\right]
$$

where $i_{H \alpha}$ and $i_{H \beta}$ represent the harmonic current components in $\alpha-\beta$ coordinates, respectively. From (11), the inverse matrix expressed as (12) is executed to produce the required harmonic current in $\alpha-\beta$ coordinates.

$$
\left[\begin{array}{c}
i_{H_{\alpha}} \\
i_{H_{\beta}}
\end{array}\right]=\frac{1}{v_{\alpha}^{2}+v_{\beta}^{2}}\left[\begin{array}{cc}
v_{\alpha} & -v_{\beta} \\
v_{\beta} & v_{\alpha}
\end{array}\right]\left[\begin{array}{c}
P_{\mathrm{ac}} \\
Q
\end{array}\right]
$$


Subsequently, inverse Clarke-transformation as presented in (13) is applied to transform $i_{H_{\alpha \beta}}$ in $\alpha-\beta$ coordinates back to three-phase harmonic current $i_{H_{a b c}}$. It will then be applied in (5) to obtain the reference injection current $i_{\text {inj,ref }}$ as desired.

$$
\left[\begin{array}{l}
i_{H_{a}} \\
i_{H_{b}} \\
i_{H_{c}}
\end{array}\right]=\sqrt{\frac{2}{3}}\left[\begin{array}{cc}
1 & 0 \\
-\frac{1}{2} & \frac{\sqrt{3}}{2} \\
-\frac{1}{2} & -\frac{\sqrt{3}}{2}
\end{array}\right]\left[\begin{array}{l}
i_{H_{\alpha}} \\
i_{H_{\beta}}
\end{array}\right]
$$

In addition, comparative study on the characteristics of each harmonic extraction algorithm is performed and their respective unique characteristics are listed in Table 1.

Table 1. Distinctive features of each time domain harmonic extraction algorithm

\begin{tabular}{ccc}
\hline Features & Time-domain Harmonic Extraction Algorithm \\
& SRF Algorithm & PQ Theory Algorithm \\
\hline Input variable & Voltage and Current & Voltage and Current \\
Transformation principle & Park Transformation & Transformation \\
Number of numerical filters & 2 low pass filters & low pass filter \\
Additional Computational Task & Synchronizer is required to deliver & Voltage preprocessing is required for active \\
& synchronizing angle & and reactive power calculation \\
Algorithm Complexity & Less complexity & Higher complexity (requires additional \\
(Exclude Filters) & active and reactive power calculation)
\end{tabular}

\section{RESULTS AND DISCUSSION}

In this work, the harmonic extraction technique is investigated by using MATLAB-Simulink platform. For testing and evaluating the performance of the harmonic extraction techniques, a SAPF power system feeding three forms of nonlinear rectifier loads is applied. For the power system setting, the three-phase power supply is fixed at $400 \mathrm{Vrms}, 50 \mathrm{~Hz}$, the switching frequency is $25 \mathrm{kHz}$, the DC-link capacitor of SAPF is $3300 \mu \mathrm{F}$, the DC-link voltage is $880 \mathrm{~V}$ and the filter inductor is $5 \mathrm{mH}$. Note that the configuration of the three nonlinear loads are:

- Three-phase diode bridge rectifier with a $\mathrm{R}$ (resistive) load (50 $\Omega$ resistor).

- Three-phase diode bridge rectifier with a series RL (inductive) load (30 $\Omega$ resistor and $50 \mathrm{mH}$ ).

- Three-phase diode bridge rectifier with a parallel a RC (capacitive) load ( $50 \Omega$ resistor and $2200 \mu \mathrm{F}$ capacitor).

Comparative evaluation is presented distinctively according to steady-state conditions and dynamic-state conditions. In steady-state conditions, the effectiveness of each harmonic extraction technique is assessed based on THD value which must be less than $5 \%$ according to IEEE Standard [30]. Meanwhile, in dynamic-state condition, the effectiveness of each harmonic extraction technique is analyzed in terms of the demonstrated response time.

\subsection{Comparative analysis for dynamic-state and steady-state conditions}

The results presented in this paper are focusing on both the accuracy (THD performance under steady-state condition) and speed (response time under dynamic-state condition) of harmonic extraction algorithms. In order to conduct equivalent comparison for both SRF and PQ theory algorithms, the numerical filter used in the algorithms is fixed in the analysis as second order Butterworth-type LPF with $10 \mathrm{~Hz}$ cutting frequency. This filter's configuration, which exhibits fast dynamic response, is chosen since it is widely applied and is reported as the most relevant filter to detect fundamental components without an error [19, 20]. Figure 3 shows the simulation waveforms of three-phase source voltage $v_{S}$, load current $i_{L}$, and source current $i_{S}$ demonstrated by SAPF while applying each harmonic extraction algorithm for capacitive load. Meanwhile, Figure 4 shows the similar simulation waveforms of $v_{S}, i_{L}$, and $i_{S}$ obtained for inductive load. Figure 5 shows the similar simulation waveforms of $v_{S}, i_{L}$, and $i_{S}$ for resistive load. In addition, Table 2 summarizes the corresponding THD values of source current $i_{S}$ demonstrated by SAPF while applying each harmonic extraction algorithm.

Based on the findings obtained, it can clearly be observed that the connection of capacitive, inductive and resistive loads has created a high harmonics distortion to the power system where a high THD value of $62.30 \%, 26.07 \%$, and $27.48 \%$ are recorded, respectively. However, by installing the three-level NPC inverter-based SAPF, the resulted THD value of the source current $i_{S}$ for each nonlinear load has been 
significantly reduced. It is clear that the performances of both harmonic extraction algorithms are acceptable where they are observed to have effectively controlled the SAPF in removing the generated current harmonics, and subsequently maintained the THD value of far below $5 \%$. Nevertheless, the mitigation performance demonstrated by the SAPF when using the SRF algorithm is superior compared to performance of SAPF when using the PQ theory algorithm. This is indicated by the lower THD value of source current $i_{S}$ achieved. More importantly, for all the nonlinear load settings, both harmonic extraction algorithms are capable of producing a mitigated source current $i_{S}$ that operates in-phase with the supply voltage $v_{S}$. This leads to almost unity power factor.

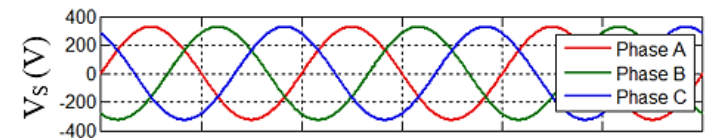

(a)

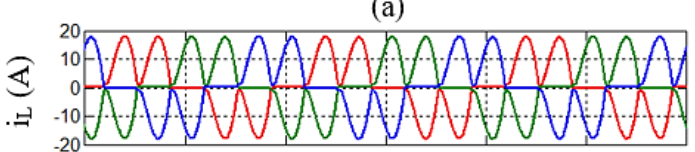

(b)

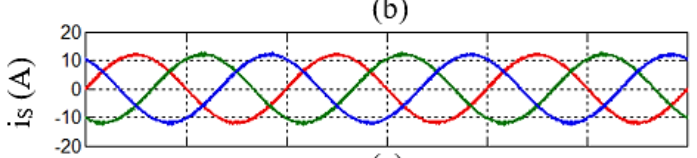

(c)

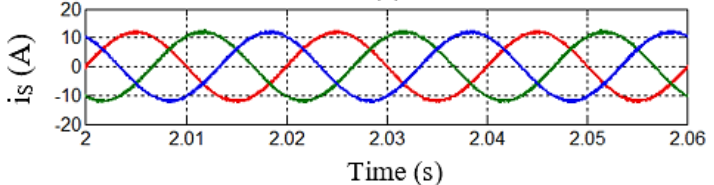

(d)

Figure 3. Simulation waveforms obtained for capacitive load: (a) source voltage $v_{S}$,

(b) load current $i_{L}$, (c) source current $i_{S}$ demonstrated

by SRF algorithm, and (d) source current $i_{S}$ demonstrated by PQ theory algorithm

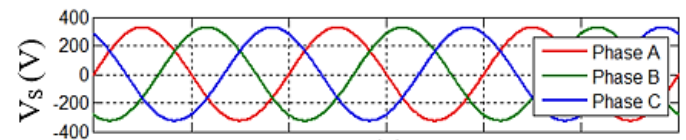

(a)

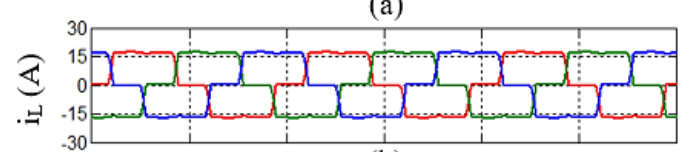

(b)

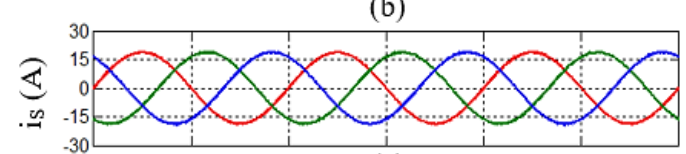

(c)

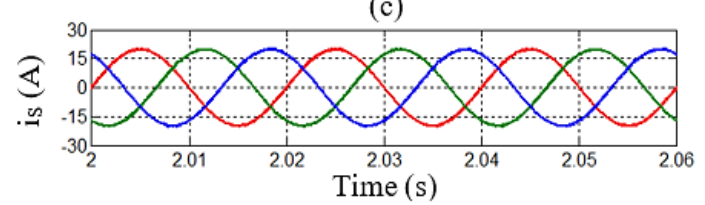

(d)

Figure 4. Simulation waveforms obtained for inductive load: (a) source voltage $v_{S}$,

(b) load current $i_{L}$, (c) source current $i_{S}$ demonstrated by SRF algorithm, and (d) source current $i_{S}$ demonstrated by PQ theory algorithm

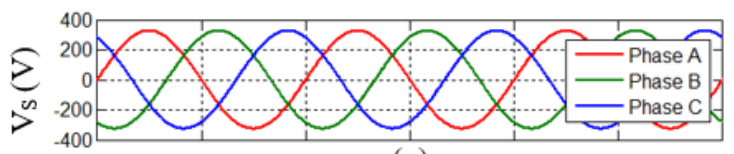

(a)

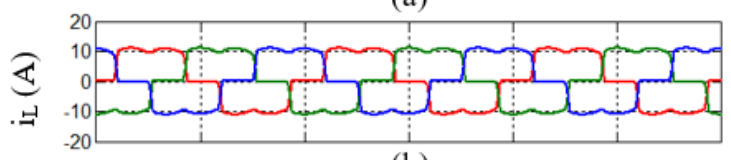

(b)

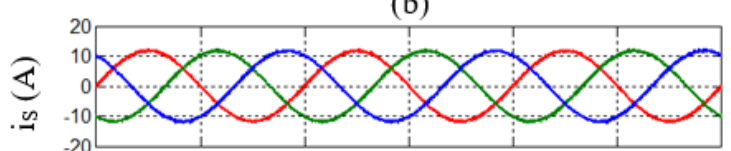

(c)

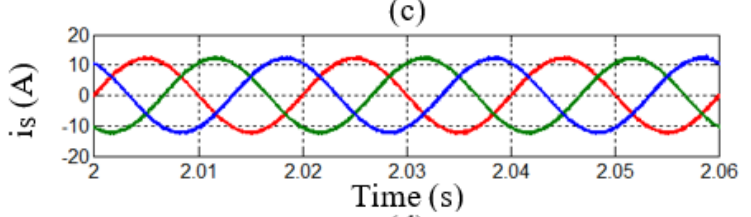

(d)

Figure 5. Simulation waveforms obtained for resistive load: (a) source voltage $v_{S}$,

(b) load current $i_{L}$, (c) source current $i_{S}$ demonstrated by SRF algorithm, and

(d) source current $i_{S}$ demonstrated by PQ theory algorithm 
Table 2. Comparison of THDs of source current $i_{S}$ obtained for capacitive, inductive and resistive nonlinear loads

\begin{tabular}{ccccccccc}
\hline $\begin{array}{c}\text { Harmonic } \\
\text { Extraction } \\
\text { Algorithm }\end{array}$ & Capacitive & $\begin{array}{c}\text { Phase A } \\
\text { Inductive }\end{array}$ & Resistive & Capacitive & $\begin{array}{c}\text { Thase B } \\
\text { Inductive }\end{array}$ & Resistive & Capacitive & $\begin{array}{c}\text { Phase C } \\
\text { Inductive }\end{array}$ \\
\hline Resistive
\end{tabular}

Figures 6 and 7 present the simulation results obtained for the evaluation performed under dynamic-state conditions of capacitive to inductive and inductive to resistive, respectively. From the findings, dynamic behaviour of SAPF while using the SRF algorithm is superior than the dynamic behaviour demonstrated by SAPF while using the PQ theory algorithm, where response time of $0.04 \mathrm{~s}$ and $0.05 \mathrm{~s}$ are recorded, respectively. Therefore, based on the evaluation conducted under steady-state and dynamic-state conditions, the findings revealed that SAPF can perform better when applying SRF algorithm as compared to PQ theory algorithm, indicated by lower THD value and faster response time. Generally, SRF algorithm is designed with reduced computational efforts where its operation only involves current calculation. Although it requires additional synchronizer algorithm to ensure proper synchronization with voltage signal, the synchronization process is executed in parallel with the current harmonic extraction process and thus does not impose additional delay. In contrast, harmonic extraction algorithm based on PQ theory requires series of complex mathematical calculations involving additional voltage and power calculation, thereby imposing excessive delay to the overall harmonic extraction process.

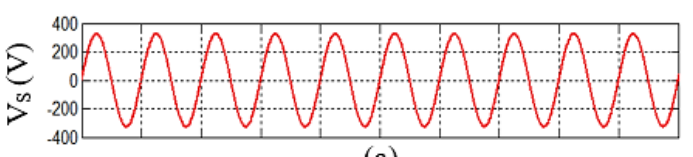

(a)

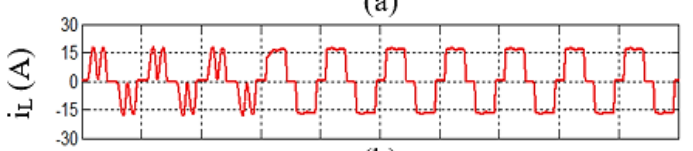

(b)

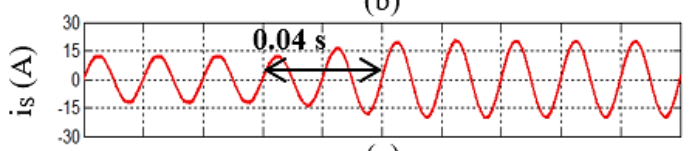

(c)

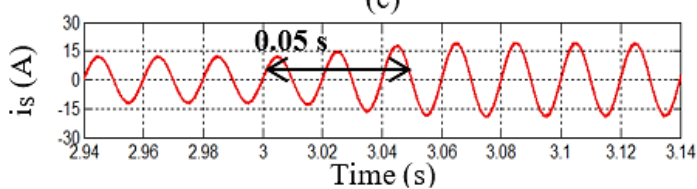

(d)

Figure 6. Phase A simulation results obtained for dynamic-state condition of capacitive to inductive: (a) source voltage $v_{S}$, (b) load current $i_{L}$, (c) source current $i_{S}$ demonstrated by SRF algorithm, and (d) source current $i_{S}$ demonstrated by PQ theory algorithm

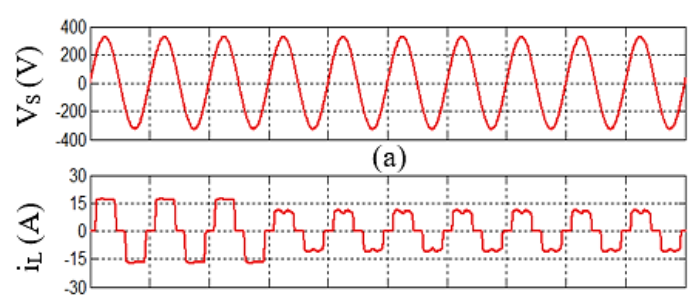

(b)

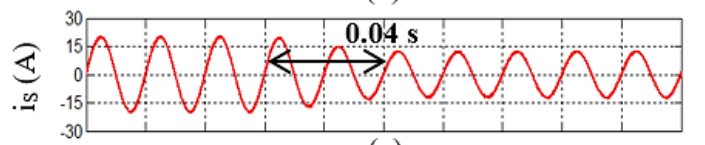

(c)

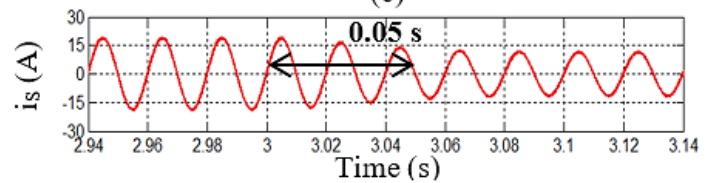

(d)

Figure 7. Phase A simulation results obtained for dynamic-state condition of inductive to resistive: (a) source voltage $v_{S}$, (b) load current $i_{L}$, (c) source current $i_{S}$ demonstrated by SRF algorithm, and (d) source current $i_{S}$ demonstrated by PQ theory algorithm

\subsection{Effect of cutting frequency variation}

For this analysis, the cutting frequency values of LPF applied in both algorithms are varied accordingly to investigate its effects on mitigation performance of SAPF. Table 3 summarizes the THD value of mitigated source current and response time achieved by SAPF utilizing each harmonic extraction algorithm for different cutting frequency values. Additionally, the findings obtained are graphically presented 
as Figures 8 and 9, providing clear picture on the relationship between cutting frequency of LPF and mitigation performances of SAPF.

Based on Figures 8 and 9, it is clear that LPF with lower cutting frequency improves THD performance of SAPF, but longer time delay is observed during mitigation process, as indicated in Table 3. In contrast, LPF with higher cutting frequency provides faster mitigation performance, but it degrades THD performance of SAPF. In other words, cutting frequency of LPF is observed to vary directly with THD value of mitigated source current $i_{S}$ and inversely with response time of SAPF. Moreover, the findings obtained also show that SAPF utilizing SRF algorithm provides better mitigation performance in term of THD value and response time as compared to PQ theory algorithm for all selected values of cutting frequency, thereby once again supporting the superiority of SRF algorithm over PQ theory.

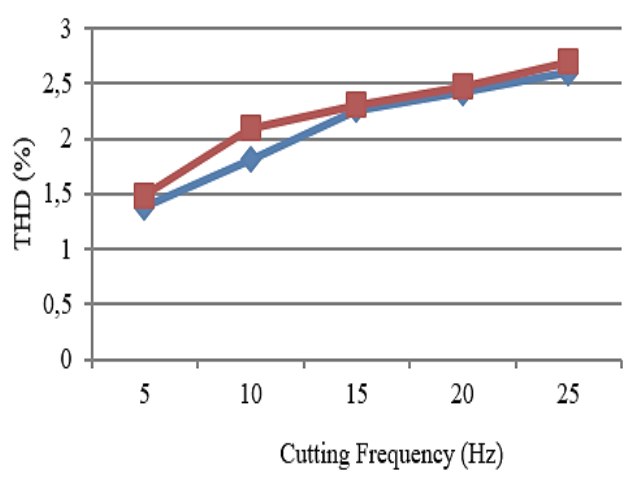

(a)

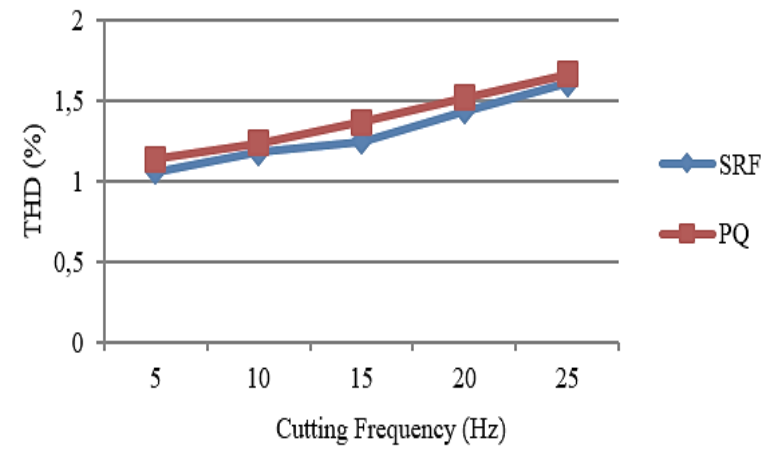

(b)

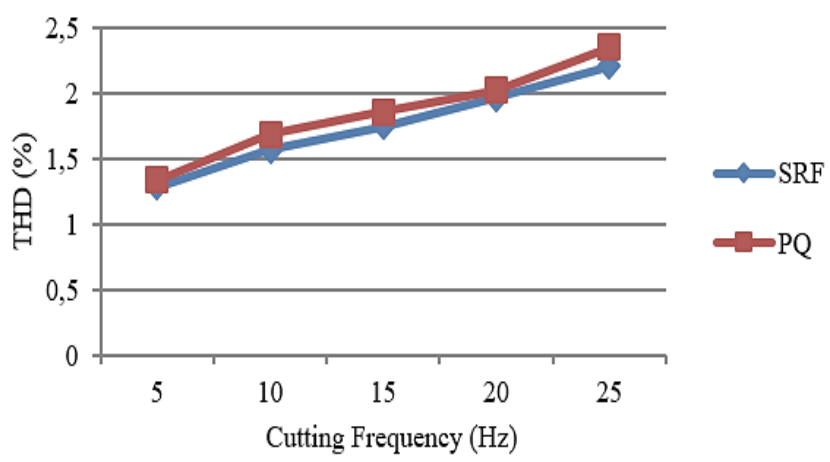

(c)

Figure 8. THD values of mitigated source current demosntrated by each harmonic extraction algorithm for different cutting frequency values of LPF under steady-state conditions,

(a) capacitive (b) inductive and (c) resistive loads

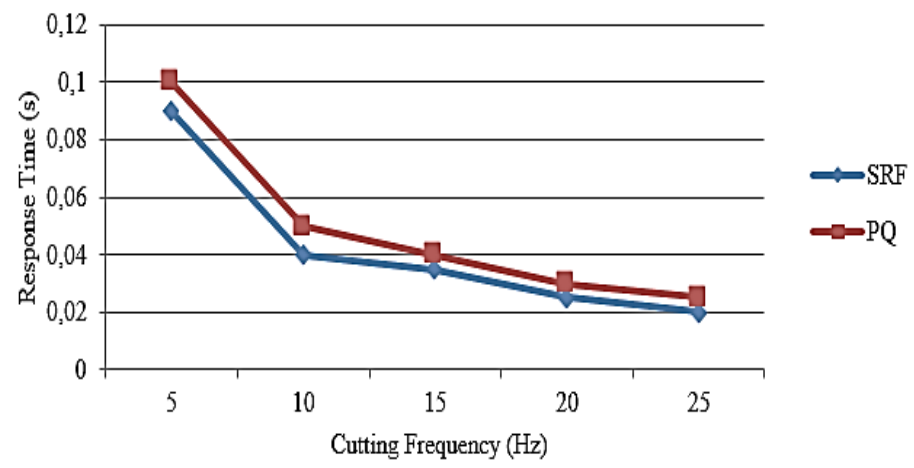

Figure 9. Response time demonstrated by each harmonic extraction algorithm for different cutting frequency values of LPF under dynamic-state conditions 
Table 3. Mitigation performances of SAPF while using each harmonic extraction algorithm for different cutting frequency values

\begin{tabular}{ccccccc}
\hline $\begin{array}{c}\text { Harmonic } \\
\text { Extraction }\end{array}$ & $\begin{array}{c}\text { Cutting } \\
\text { Frequency of } \\
\text { Algorithm }\end{array}$ & \multicolumn{3}{c}{$\begin{array}{c}\text { THD }(\%) \\
\text { Steady-state conditions }\end{array}$} & \multicolumn{2}{c}{$\begin{array}{c}\text { Response Time (s) } \\
\text { Dynamic-state conditions } \\
\text { Inductive to Resistive }\end{array}$} \\
\hline SRF & 5 & 1.38 & 1.06 & 1.29 & 0.090 & 0.090 \\
Algorithm & 10 & 1.81 & 1.18 & 1.57 & 0.040 & 0.035 \\
& 15 & 2.26 & 1.25 & 1.75 & 0.025 & 0.035 \\
& 20 & 2.42 & 1.44 & 1.97 & 0.020 & 0.100 \\
Capacitive & Inductive & Resistive & Capacitive to Inductive & 0.025 \\
PQ Theory & 25 & 2.60 & 1.61 & 2.21 & 0.050 & 0.100 \\
Algorithm & 5 & 1.49 & 1.14 & 1.34 & 0.040 & 0.050 \\
& 10 & 2.10 & 1.24 & 1.69 & 0.030 & 0.040 \\
& 15 & 2.31 & 1.37 & 1.86 & 0.025 & 0.030 \\
\hline
\end{tabular}

\section{CONCLUSION}

This manuscript has presented a thorough comparative evaluation of two famous time-domain current harmonic extraction algorithms (SRF and PQ theory) for the application in a three-phase three-level NPC inverter-based SAPF. Nevertheless, the findings obtained in this research work are valid for other SAPF configurations as well. The two algorithms are capable of controlling SAPF to mitigate current harmonics in three-phase system. However, SAPF utilizing SRF algorithm is found to always show better results under two conditions, which are steady-state conditions and dynamic-state conditions. This is basically due to its simple and fast processing features which minimize the computational delay. This paper also investigated the effect of LPF's cutting frequency variations on mitigation performance of the SAPF. The findings show that THD performance of SAPF improves with the decreased of LPF's cutting frequency, while dynamic performance of SAPF improves with the increased of LPF's cutting frequency. Therefore, in the context of SRF and PQ theory, the applied LPF must be tuned to ensure optimal performance of SAPF.

\section{ACKNOWLEDGEMENTS}

The authors are grateful to Universiti Tenaga Nasional (UNITEN) for supporting this manuscript under BOLD publication fund.

\section{REFERENCES}

[1] M. El-Habrouk, M. K. Darwish, and P. Mehta, "Active power filters: A review," IEE Proceedings of Electric Power Applications, vol. 147, no. 5, pp. 403-413, 2000.

[2] H. Akagi, "Active Harmonic Filters," Proceedings of the IEEE, vol. 93, no. 12, pp. 2128-2141, 2005.

[3] Tareen, W., et al., "Mitigation of power quality issues due to high penetration of renewable energy sources in electric grid systems using three-phase APF/STATCOM technologies: a review," Energies, vol. 11, pp. 1491, 2018.

[4] Y. Hoon, M. A. M. Radzi, and A. S. Al-ogaili, "Adaptive Linear Neural Network Approach for Three-Phase Four-Wire Active Power Filtering under Non-Ideal Grid and Unbalanced Load Scenarios," Applied Sciences, vol. 9, no. 24, pp. 5304, 2019.

[5] Y. Hoon, M. A. M. Radzi, M. K. Hassan, and N. F. Mailah, "Enhanced Instantaneous Power Theory with Average Algorithm for Indirect Current Controlled Three-Level Inverter-Based Shunt Active Power Filter under Dynamic State Conditions," Mathematical Problems in Engineering, 2016.

[6] M. A. Kamarposhti, and A. A. Hosseyni, "Modified approach for harmonic reduction in three-phase to seven-phase using transformer winding connections," International Journal of Electrical and Computer Engineering (IJECE), vol. 9, no. 3, pp. 2088-8708, 2019.

[7] S. A. Azmi, G. P. Adam, S. R. A Rahim, " Voltage-controlled of a three-phase current source inverter in islanded operation," Indonesian Journal of Electrical Engineering and Computer Science, vol. 16, no. 1, pp. 156-164, 2019.

[8] A. Chaithanakulwat, "Development of DC voltage control from wind turbines using proportions and integrals for Three-phase grid-connected inverters," International Journal of Electrical and Computer Engineering (IJECE), vol. 10, no. 2, pp. 1701-1711, 2020.

[9] A. Bhattacharya, C. Chakraborty, and S. Bhattacharya, "Shunt compensation - Reviewing Traditional Methods of Reference Current Generation," IEEE Industrial Electronics Magazine, vol. 3, no. 3, pp. 38-49, 2009.

[10] L. Asiminoaei, F. Blaabjerg, and S. Hansen, "Detection is key - Harmonic detection methods for active power filter applications," IEEE Industrial Applications Magazine, vol. 13, no. 4, pp. 22-33, 2007.

[11] Sen Ye, et al., "Shunt active power filter based on proportional integral and multi vector resonant controllers for compensating nonlinear loads," Journal of Electrical and Computer Engineering, vol. 2018, no. 5, pp. 1-11, 2018.

[12] M. Bouziane, and M. Abdelkader, "Direct space vector modulation for matrix converter fed dual star induction machine and neuro-fuzzy speed controller," Bulletin of Electrical Engineering and Informatics, vol. 8, no. 3, pp. 818-828, 2019. 
[13] M. M. Almelian, I. I. Mohd, A. Z. Ahmad, M. Salem, M. A. Omran, A. Jusoh, and T. Sutikno, "Enhancing the performance of cascaded three-level VSC STATCOM by ANN controller with SVPWM integegration," International Journal of Electrical and Computer Engineering (IJECE), vol. 9, no. 5, pp. 3880-3890, 2019.

[14] R. S. Rani, C. S. Rao, and M. V. Kumar, "Reduction of Current Harmonics by Cascaded Multilevel Inverter based Shunt Active Power Filters," International Journal of Recent Technology and Engineering, vol. 8, no. 5, pp. 4952-4961, 2020.

[15] M. Kashifa, M. J. Hossaina, F. Zhuob, and S. Gautamc, "Design and implementation of a three-level active power filter for harmonic and reactive power compensation," Electric Power Systems Research, vol. 165, pp. 144-156, 2018.

[16] A. Pigazo, V. M. Moreno, and E. J. Estebanez, "A Recursive Park Transformation to Improve the Performance of Synchronous Reference Frame Controllers in Shunt Active Power Filters," IEEE Transactions on Industrial Electronics, vol. 24, no. 9, pp. 2065-2075, 2009.

[17] M. Monfared, S. Golestan, and J. M. Guerrero, "A New Synchronous Reference Frame-Based Method for Single-Phase Shunt Active Power Filters," Journal of Power Electronics, vol. 13, no. 4, pp. 692-700, 2013.

[18] N. Eskandarian, Y. A. Beromi, and S. Farhangi, "Improvement of Dynamic Behavior of Shunt Active Power Filter Using Fuzzy Instantaneous Power Theory," Journal of Power Electronics, vol. 14, no. 6, pp. 1303-1313, 2014.

[19] M. Popescu, A. Bitoleanu, and V. Suru, "A DSP-based implementation of the p-q theory in active power filtering under nonideal voltage conditions," IEEE Transactions on Industrial Informatics, vol. 9, no. 2, pp. 880-889, 2013.

[20] T. C. Green, and J. H. Marks, "Control techniques for active power filters," IEE Proceedings of Electric Power Applications, vol. 152, no. 2, pp. 369-381, 2005.

[21] C. H. Ng, K. Busawon, G. A. Putrus, and L. Ran, "Fast-individual-harmonic-extraction technique," IEEE Proceedings on Generation, Transmission and Distribution, vol. 152, no. 4, pp. 556-562, 2005.

[22] P. Dey, and S. Mekhilef, "Synchronous reference frame based control technique for shunt hybrid active power filter under non-ideal voltage," Innovative Smart Grid Technologies-Asia (ISGT Asia), pp. 481-486, 2014.

[23] S. S. Wamane, J. R. Baviskar, and S. R. Wagh, "A Comparative Study on Compensating Current Generation Algorithms for Shunt Active Filter under Non-linear Load Conditions," International Journal of Scientific and Research Publications, vol. 3, no. 6, pp. 1-6, 2013.

[24] A. Mortezaei, C. Lute, M. G. Simoes, F. P. Marafao, and A. Boglia, "PQ, DQ and CPT control methods for shunt active compensators-A comparative study," Energy Conversion Congress and Exposition (ECCE), pp. 2994-3001, 2014.

[25] N. Jain, and A. Gupta, "Comparison between Two Compensation Current Control Methods of Shunt Active Power Filter," International Journal of Engineering Research and General Science, vol. 2, no. 5, pp. 603-615, 2014.

[26] M. Suresh, A. K. Panda, and Y. Suresh, "Fuzzy Controller Based 3Phase 4Wire Shunt Active Filter for Mitigation of Current Harmonics with Combined p-q and Id-Iq Control Strategies," Energy and Power Engineering, vol. 3, pp. 43-52, 2011.

[27] K. H. Bhalodi, and P. Agarwal, "Space Vector Modulation with DC-Link Voltage Balancing Control for Three-Level Inverters," ACEEE International Journal on Communication, vol. 1, no. 1, pp. 14-18, 2010.

[28] U.-M. Choi, and K.-B. Lee, "Neutral-Point Voltage Balancing Method for Three-level Inverter Systems with a Time-Offset Estimation Scheme," Journal of Power Electronics, vol. 13, no. 2, pp. 243-249, 2013.

[29] A. K. Gupta, and A. M. Khambadkone, "A Space Vector PWM Scheme for Multilevel Inverters Based on Two-Level Space Vector PWM," IEEE Transactions on Industrial Electronics, vol. 53, no. 5, pp. 1631-1639, 2006.

[30] IEEE Standard 519, "IEEE Recommended Practice and Requirement for Harmonic Control in Electric Power Systems," IEEE Std 519-2014 (Revision of IEEE Std 519-1992), pp. 1-29, 2014.

\section{BIOGRAPHIES OF AUTHORS}

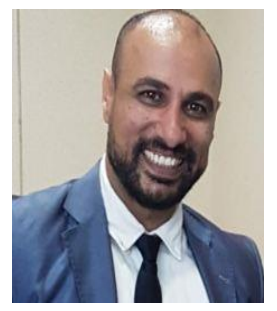

Ali Saadon Al-Ogaili received his B.Sc. degree in Electrical Engineering from Baghdad University, Baghdad, Iraq, in 2005, and M.Sc. degree and Ph.D. degree in Electrical Power Engineering from Universiti Putra Malaysia (UPM), Serdang, Selangor, Malaysia, in 2012 and 2018, respectively. He is currently a Post-Doctoral Researcher in Institute of Power Engineering (IPE) in Tenaga Nasional university (UNITEN). His research interests include power electronic circuit design and simulation, electric vehicles, and solar energy.

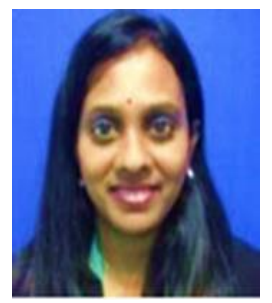

Agileswari K. Ramasamy was born in Taiping, Perak and received her B. Sc (Engineering) degree from Purdue University, USA in 1995 under the sponsorship of Yayasan Tenaga Nasional. She obtained her MSc. (Control System) from Imperial College, London in 2001 and $\mathrm{PhD}$ in Electrical Engineering from Universiti Tenaga Nasional (UNITEN), under the sponsorship of UNITEN. She is currently an Associate Professor in the Department of Electronics Communication Engineering at UNITEN and serving as a Deputy Dean of Research and Postgraduate for College of Engineering, UNITEN. She is also a Chartered Member of the Institution of Engineering and Technology (IET). She is currently active in research and consultancy in control system, power system, power quality, energy efficiency and renewable energy. She has headed several research projects to date and has successfully published several indexed journals. 


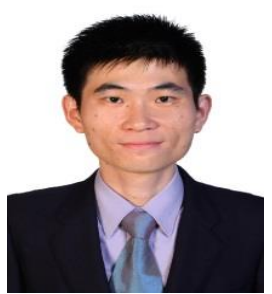

Yap Hoon was born in Sitiawan, Perak, Malaysia, in 1990. He received his B.Eng. degree in Electrical and Electronic Engineering and Ph.D. degree in Electrical Power Engineering from Universiti Putra Malaysia (UPM), Serdang, Selangor, Malaysia, in 2013 and 2017, respectively. After completing his Ph.D., he served as Post-Doctoral Researcher at Advanced Lightning, Power and Energy Research (APLER) Centre, UPM. He is currently a Lecturer at Taylor's University. His research and teaching interests include power electronics, power quality, and multilevel inverter.

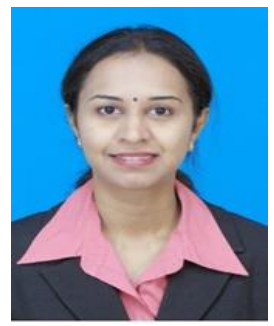

Renuga Verayiah received her Bachelor of Electrical \& Electronics Engineering Degree in 2002 and Master of Electrical Engineering in 2007 from the University Tenaga Nasional, Malaysia. She obtained her PhD degree in Electrical, Electronics \& System Engineering in 2017 from Universiti Kebangsaan Malaysia, Malaysia. Renuga is currently serving as a senior lecturer at Department of Electrical \& Electronics Engineering, UNITEN and also as a Program Coordinator for Master of Electrical Engineering Program at College of Graduate Studies, UNITEN. She is a member of Institute of Engineering and Technology UK (MIET) and The Institution of Engineers Malaysia (IEM). She is also a Certified Energy Manager and a technical working committee for country's National GHG inventory and International Consultation \& Analysis (ICA) (BUR2) Malaysia. Her research interest includes power system steady state analysis, power system dynamic analysis, power system optimization and energy efficiency.

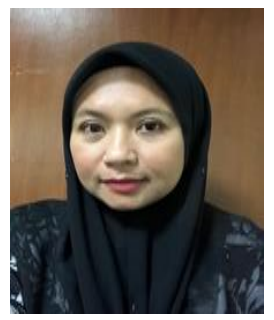

Marayati Binti Marsadek received her Bachelor of Electric Power and master's in electrical engineering from The National Energy University. She was awarded with $\mathrm{PhD}$ in Electrical, Electronics and System Engineering from the National University in 2011. She is a Director of Institute of Power Engineering (IPE) and Senior Lecturer in the Department of Electric Power at The National Energy University. Her research interest includes power system stability, active network management and risk assessment. She has been actively involved in research and consultancies work related to energy, demand side respond, power system stability and renewable energy. She has written more than 10 guidelines and manuals used by engineers in Tenaga Nasional Berhad (TNB).

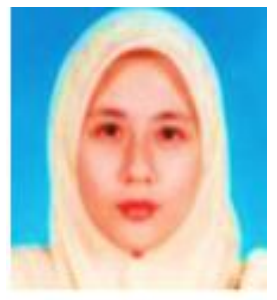

Tengku Juhana was born in Kuantan, Pahang, Malaysia in May 1979. She received her B. Eng. In Electrical Power Engineering in 2002 and Master's in Electrical Engineering in 2004 from Universiti Tenaga Nasional (UNITEN), Selangor, Malaysia. She obtained her PhD in Electrical, Electronics and Systems Engineering from Universiti Kebangsaan Malaysia (UKM), Bangi Malaysia in 2014 specializing in the area of optimization of voltage control methods in an active distribution system. Her current research interest includes power quality and optimization in power system analysis.

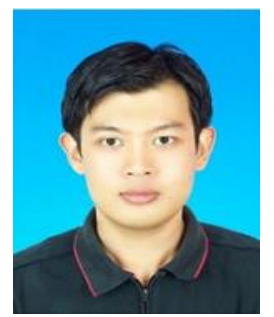

Nur Azzammudin Rahmat received his $\mathrm{PhD}$ in Power System Engineering from Universiti Teknologi MARA in 2016. Currently, he is a senior lecturer at College of Engineering, Universiti Tenaga Nasional (UNITEN). He is also the project manager for UNITEN Smart UniverCity. His research area covers renewable energy, smart city, power system study, and computational intelligence. 